\title{
COMUNICAÇÃO, DEBATE PÚBLICO E GRUPOS DE PRESSÃO: UMA REFLEXÃO SOBRE GÊNERO E VIO- LÊNCIA NO PLANO NACIONAL DE EDUCAÇÃO
}

\section{Caio Ramos da Silva' \\ Ricardo Cortez Lopes ${ }^{2}$}

Resumo: Investigamos o modo como se estabeleceu parte do debate público sobre gênero e sexualidade em relação ao Plano Nacional de Educação (PNE). Os indicadores foram manifestações de grupos de pressão, interações e conteúdos das notícias de grandes portais. Nosso aparato conceitual para analisar essas manifestações virtuais foram alguns conceitos da teoria da modernização (como a separação público-privado) para perceber o quanto o debate público deles se aproximou. Por fim, refletimos sobre como essas ideias encontradas reverberam no contexto brasileiro, considerando os altos números de crimes contra LGBT, lançando pistas para se pensar em termos de políticas públicas e de legislação. Palavras-Chave: Plano Nacional de Educação; Debate público; Opinião Pública; Gênero.

Abstract: We investigate how part of the public debate on gender and sexuality was established in relation to the National Education Plan (PNE). The indicators were: manifestations of pressure groups, interactions and news content from large portals. Our conceptual apparatus for analyzing these virtual manifestations were some concepts of modernization theory (such as public-private separation) to realize how much their public debate has approached to that modern ideas. Finally, we reflect about how these ideas founded reverberate in Brazilian context, considering the high numbers of crimes against LGBT, throwing clues to think in terms of public policies and legislation. Keywords: National Education Plan; Public debate; Public opinion; Gender.

\section{Introdução: um problema social e as políticas públicas}

Estudos apontam que o cenário brasileiro tem se mostrado, estatisticamente, muito hostil às diversidades sexuais e de expressão de gênero ${ }^{3}$. Ano após ano, os

\footnotetext{
1 Mestrando do Programa de Pós Graduação em Comunicação e Informação da UFRGS. E-mail: ramoss.caio@ gmail.com.

2 Doutorando do Programa de Pós Graduação em Sociologia da UFRGS. E-mail: rshicardo@hotmail.com.

3 Não partimos de um conceito de gênero específico, mas sim investigamos a sua formulação pelos atores em uma relação de embate epistemológico entre as suas perspectivas.
} 
indices crescentes de violência e de marginalização contra as populações de Lésbicas, Gays, Bissexuais e Transgêneros (LGBT) têm mobilizado organizações e militantes a manifestar-se publicamente com o objetivo de pressionar as diferentes instâncias de governo no Brasil para elaboração de políticas públicas que sejam mais inclusivas. Porém, merece destaque a observação que tal pressão não foi exercida apenas pelos ativistas em prol dos direitos LGBTs como também por outros grupos sociais.

São dados trazidos por organizações como a Transgender Europe, que denotam que o Brasil ocupa o primeiro lugar nos seus indicadores, ou seja, tornamo-nos o país que mais registra mortes de travestis e de transexuais, sendo responsável, sozinho, por $40 \%$ desses crimes cometidos no mundo. Pesquisas em âmbito nacional apontam que somente no ano de 2015 foram registrados 318 assassinatos de pessoas LGBTs no país, segundo relatório do Grupo Gay da Bahia ${ }^{4}$. Ainda, segundo a nota técnica $n^{\circ} 24 / 2015$ do Ministério da Educação divulgando os resultados de um estudo realizado em parceria com a Universidade de São Paulo em 501 escolas dos 27 estados - com a participação de 18.599 pessoas da comunidade escolar (entre estudantes, responsáveis, professores/as, diretores/as e outros profissionais) - apontou que $93,5 \%$ das pessoas entrevistadas apresentaram algum nivel de preconceito com relação às questões de gênero e $87,3 \%$ demonstraram ter algum tipo de preconceito quanto à orientação sexual.

No entanto, desde 2004 existem registros de novos esforços no sentido de mudar essa realidade através da implementação de políticas públicas focadas em temáticas como as de gênero. É importante ressaltar que pautar a administração pública por intermédio dessas políticas implica uma definição específica sobre as funções estatais:

Não existe uma única, nem melhor, definição sobre o que seja política pública. Mead (1995) a define como um campo dentro do estudo da política que analisa o governo à luz de grandes questões públicas e Lynn (1980), como um conjunto de ações do governo que irão produzir efeitos específicos. Peters (1986) segue o mesmo veio: política pública é a soma das atividades dos governos, que agem diretamente ou através de delegação, e que influenciam a vida dos cidadãos. Dye (1984) sintetiza a definição de política pública como "o que o governo escolhe fazer ou não fazer". A definição mais conhecida continua sendo a de Laswell, ou seja, decisões e análises sobre política pública implicam responder às seguintes questões: quem ganha o quê, por quê e que diferença faz (SOUZA, 2006, p. 24).

Vamos reter dessas ideias a noção de que políticas públicas são ações que partem diretamente do governo e que visam influenciar a vida de seus cidadãos. 
Assim, significa que a sexualidade (e questões de gênero relacionadas) deixou de ser considerada como um assunto completamente privado e tornou-se objeto de cuidados públicos/estatais.

Um marco nesse sentido foi o lançamento do projeto "Brasil sem Homofobia", em 2004, que estabeleceu uma agenda de ações específicas voltadas à área de educação. Em decorrência desse primeiro projeto, foi criado o projeto "Escola Sem Homofobia", cuja medida mais notória foi o lançamento, em 2011, de um kit de materiais e de atividades didáticas cujas orientações voltavam-se para o enfrentamento da LGBTfobia - o medo ou aversão a pessoas pertencentes ao segmento LGBT. A divulgação e posterior distribuição desse material conflagrou discussões acirradas e grandes polêmicas para os debates públicos sobre essas temáticas e acabou sendo pejorativamente apelidado de "kit gay" por alguns atores sociais.

Sabemos que a repercussão negativa e forte oposição social visibilizada no debate público resultou na rejeição da medida. Nosso interesse é justamente entender esse debate no tocante a grupos de pressão que realizaram ações em espaços formais, informais e repercutiram os resultados. Esses grupos, que denominaremos como conservadores - são geralmente ligados às igrejas evangélicas neopentecostais que mobilizaram-se no sentido de evitar a distribuição do material didático, contando com o apoio de alguns setores da imprensa. Em decorrência dessas ações ou motivado por (re)ações a exemplo dessa, o Governo Federal decidiu não mais distribuir o material para as escolas.

\section{Modernidade e democracia: elementos sistêmicos para ○ debate público}

A noção de debate público (e de sua necessidade) possui um grande lastro tanto filosófico quanto social, partindo de um diagnóstico que pretende-se como normativo: a teoria da modernização. Denota-se que seu início se deu em meio ao esforço iluminista pela criação de dualismos (LATOUR, 1994) em busca da purificação das esferas de ação que inclui um sistema institucional e civil para o alcance de uma razão universal(izável).

Baseando-se naquilo que considerou ser do escopo da razão, a modernidade buscou descontextualizar o conhecimento, tornando-o universal ao promover a separação entre o público (o reino da objetividade e da eternidade) e o privado (o reino da subjetividade e da mudança). Nesse sentido, o público é obtido na purificação, a partir da deliberação entre razões inatas. Se pensada a partir desse modelo, a imprensa e demais meios de comunicação cumprem o papel de informar aos cidadãos para que estes possam entrar adequadamente em deliberação, que por sua vez permite que se alcance a autonomia moral (JOVCHELOVITCH, 2011; EISENSTALDT, 2001). As dimensões do público e do privado constituem assim um dos fundamentos base da modernidade uma vez que, como defende-se aqui, quando a esfera pública - fundamentalmente 
política - é atravessada por opiniões e interesses de cunho privado, o aspecto político e racional do debate público é perdido.

Hannah Arendt, em seu livro A Condição Humana (1958) discute e analisa dois dos conceitos clássicos da filosofia grega para entender, sobretudo, o surgimento do espaço social nas sociedades modernas, a saber, a esfera pública e a esfera privada. Para ela, é imprescindivel a separação nítida e rigorosa dessas duas esferas porque é dessa separação que nasce a condição principal para a atividade política: a ação.

A ação é a atividade política por excelência, recebendo especial atenção de Arendt (1958) reportando-se a Aristóteles como referência fundamental. Aristóteles (2002), no sexto livro de sua Ética A - Nicômaco, diferencia o que diz respeito a categoria do agir do que seria parte do escopo do fazer. $O$ que o pensador grego visa é definir a ação enquanto imbuída de valores morais, ou seja, a ação é relativa a ética porque é passivel de responsabilização e valoração moral. Portanto, em sua perspectiva as ações assim como as escolhas são feitas tendo em vista o que é bom. No que concerne ao âmbito da política, visamos o que é bom para todos, um bem comum denotando que as nossas ações sempre pressupõem a existência de um "outro". Busca-se sustentação, assim, a ideia de que o agir humano é sempre ético e político.

No pensamento aristotélico, o homem é um animal naturalmente político, pois é no espaço público, que ele poderia atingir a excelência especifica da sua condição humana. Por outro lado, a esfera privada corresponde ao espaço do lar, à propriedade do cidadão e ao seu modo de subsistência, ou seja, a tudo aquilo que é pertinente ao sustento do homem, desde sua economia doméstica até mesmo o seu trabalho. Nesse sentido há uma separação radical entre as necessidades do homem (o privado), do mesmo quando no exercício da atividade nobre da política (pública). Portanto, percebe-se que a esfera pública era a prioridade, mesmo que condicionada por elementos da esfera privada, visto que apenas aquele que dispunha de posses e escravos podiam dedicar-se aos debates na pólis. Diante disso, valoriza-se o trabalho como algo necessário para que fossem alcançados os direitos como cidadão (ressalva-se, no entanto, que a atividade humana por excelência estava na ação política).

Com o surgimento da esfera social, Arendt (2003) observa, que o trabalho passa ocupar certa centralidade na organização da vida: "A sociedade é a forma na qual o fato da dependência mútua em prol da subsistência, e de mais nada, adquire importância pública, e na qual as atividades que dizem respeito à mera sobrevivência são admitidas em praça pública" (ARENDT, 2003, p.56).

A esfera social, a partir da instituição do Estado moderno e burguês acompanha a redução progressiva do espaço público e o crescimento dos interesses do espaço privados assumindo importância pública. Um exemplo disso, como bem 
observa Gomes (2008) e Esteves (2011), é a importância da economia e do sistema financeiro no Estado moderno. A economia, na figura do mercado, que era atividade relacionada ao âmbito doméstico e privado na pólis grega passa, no estado moderno burguês, a fazer parte do interesse coletivo, torna-se assim "publicamente relevante" (GOMES, 2008). Como consequência, a prática da comunicação pública altera-se nesse contexto, pois os interesses mercadológicos se impõem, tanto por parte da imprensa quanto por parte dos indivíduos. É nesse contexto que se instauram os meios de comunicação de massa que se apresentam como uma "nova forma de sociabilidade do mundo moderno" (ESTEVES, 2011).

Entende-se que decorre disso o processo de massificação social que transforma e desfigura a estrutura do espaço público. Além disso, a partir do estado moderno, fortalecem-se as ideias de não intervenção do estado na economia e do direito à propriedade privada, colocando em evidencia que a economia, antes restrita à esfera privada para os gregos, ascende à esfera pública. Importante notar que, ao defender a não intervenção do estado na economia, o individuo inserido na sociedade faz uso do espaço público para defender um interesse de âmbito do privado. Conforme Arendt (2003), provoca-se, com este cenário, um certo deslocamento das fronteiras do público em direção as do privado. No mesmo sentido, como afirma Esteves (2011), há uma expansão do privado que estabelece uma relação de supremacia frente ao público. Com isso, a noção de esfera pública perde em sentido político, pois a participação na esfera pública já não é mais motivada por uma deliberação sobre o bem comum; essa participação passa a ser motivada por interesses dos privados. Ainda assim, é possivel observar que,

\begin{abstract}
a liberalização da sociedade e do Estado é vista como uma remoção de obstáculos aos plenos desenvolvimento e afirmação do indivíduo. De uma outra forma bem diferente, pois, da função política do espaço público clássico, regido por uma estética da existência, em que a apresentação perante os outros era, antes de mais, uma forma de superação do indivíduo, de este ganhar notoriedade e alcançar uma glorificação (pelo seus belos discursos e actos grandiosos em público) (ESTEVES, 2011, p.180).
\end{abstract}

Dito de outro modo, a participação política que na pólis grega tinha como condição a liberdade de cada cidadão, ganha, a partir do estado moderno novas configurações das esferas do público e do privado. Provoca-se, assim, uma outra constituição da noção de liberdade, que adquire um sentido individualista, distanciando-se da ideia clássica do homem livre enquanto cidadão por meio do reconhecimento de seus pares, da ação política e no espaço público da Pólis.

Embora possa-se concordar que exista um declínio do espaço público no sentido da antiguidade clássica, no estado moderno instituído a partir de uma consolidação da classe burguesa, a racionalidade do debate público ainda é elemento imprescindivel e um dos seus pressupostos. Esteves (2011) afirma que o uso 
público da razão é o que caracteriza o espaço público, realizando-se por meio das práticas comunicacionais: na publicidade e na crítica às opiniões em jogo no debate, ou seja, ela é "os contextos próprios para regular o exercício de tais práticas" (ESTEVES, 2011, p.190). Esteves considera ainda certa "qualificação moral" que compõe e legitima o uso público da razão.

O espaço público no Estado Moderno é o âmbito da publicidade necessariamente submetido à crítica. Publicidade e crítica aqui são entendidas como práticas comunicacionais que caracterizam um processo do qual decorre a opinião pública. A crítica é o que garante razoabilidade ao que é debatido, e todo debate público pressupõe esse processo. Segundo Esteves (2011) a opinião pública é um consenso que se estabelece ao superar a crítica e o debate no espaço público. Desse modo, é a opinião pública que legitima as leis no estado burguês e democrático de direito (GOMES, 2008).

Para o autor, a motivação da imprensa em sua origem era marcadamente política. Desse modo, a imprensa também se orientava no sentido de uma comunicação essencialmente racional, e somente com o aprofundamento do capitalismo e a consolidação de uma Indústria Cultural a mídia passou a ser mídia de massa. Com isso, grandes veículos de imprensa tornam-se propriedade de grandes corporações e suas práticas, do mesmo modo, as suas pautas passam a ser atravessados por interesses privados e direcionados ao mercado.

É nesse contexto que cabe uma distinção feita por Esteves (2011) entre informação e comunicação. Comunicação seria a "base das relações estabelecidas nos e pelos públicos" (ESTEVES, 2011, p.228), enquanto a informação seria o domínio da massa, mesmo com aparência de comunicação. Esteves entende a informação como um processo verticalizado, no qual observa-se uma elite que discute entre pares e fixa palavras de ordem, vozes de comando em relação a uma massa passiva. Com isso, para o autor, a imprensa tem um privilégio na esfera pública e "causa influência" (ESTEVES, 2011, p.50).

Gomes (2008) empreende argumentação similar em relação à comunicação de massa, mas ele ressalta que a comunicação de massa é central no debate público no estado moderno. Justamente porque dificilmente algo que é de interesse público passará ao largo dela.

\section{A discussão sobre o PNE e a importância da escola}

Um mundo onde a educação é um privilégio e o aprisionamento da consciência impede de toda maneira $o$ acesso das massas a experiência autentica das formações espirituais, já não importam tanto os conteúdos ideológicos específicos, mas o fato de que simplesmente haja algo preenchendo o vácuo da consciência expropriada e desviando a atenção do segredo conhecido por todos. (ADORNO, 2002, p.102) 
Um dos pressupostos mais basilares do estado democrático moderno é, sem dúvida, a pluralidade das ideias. Com essa compreensão, estabelece-se a intima relação entre um ambiente democrático e a discussão sobre a diversidade em seus mais variados aspectos. A escola enquanto instituição em um Estado democrático desempenha papel fundamental. Assim, a escola deve prezar, igualmente, pela multiplicidade de ideias e amplo debate sobre as mais variadas temáticas do seu contexto histórico, político e social. Além disso, a escola pode oferecer oportunidades mais igualitárias e conscientização sobre direitos e cidadania.

No entanto, em um cenário de muitas desigualdades forjadas e aprofundadas ao longo de um difícil processo histórico ${ }^{5}$, a escola brasileira tem se mostrado ineficaz enquanto espaço de formação de cidadania. Segundo Junqueira (2009), o modelo de escola e educação que tem sido corroborada legitima relações de poder, reproduz padrões sociais e consolida estereótipos parciais e negativos em relação à diferença, ao outro:

A escola configura-se um lugar de opressão, discriminação e preconceitos, no qual e em torno do qual existe um preocupante quadro de violência a que estão submetidos milhões de jovens e adultos LGBT - muitos/as dos/as quais vivem, de maneiras distintas, situações delicadas e vulneradoras de internalização da homofobia, negação, autoculpabilização, auto-aversão. E isso se faz com a ${ }^{6}$ participação ou a omissão da família, da comunidade escolar, da sociedade e do Estado. (JUNQUEIRA, 2009, p. 14).

Louro (2004, p. 33) afirma que novas práticas e novos sujeitos constituem uma "ameaça a vocação normalizadora da Educação". Para a autora, é preciso estar atento ao sujeito à margem dessa normalização enquanto invisibilizados nos saberes hegemônicos. Esses processos acabam, assim, por caracterizar-se como impositivos e normativos, de modo que consagram a diferença como algo anormal. Questionar esse processo é um primeiro e essencial passo para romper com essa lógica.

Em 2010, o Conselho Nacional de Educação elaborou um relatório, documento esse que serviria de base para o Plano Nacional de Educação. Os Planos de Educação são documentos com força legislativa que estabelecem metas para que o direito à educação de qualidade vigore em âmbito nacional no período de dez anos, nas esferas municipais, estaduais e federal, abrangendo também as instituições privadas nas mais diferentes modalidades da educação. O PNE configura-se assim como fundamental instrumento da política pública educacional. $O$ documento, conforme previsto por lei - na LDB, com a Lei número 9.394/1996 - deve ser elaborado pela União e encaminhando para discussão e votação no

\footnotetext{
5 É importante destacar que a educação passa a ser de acesso universal, somente, a partir da constituição de 1988, tornando-se direito garantido pelo estado.

6 Transgender Europe é umas das mais importantes organizações mundial que monitora a legislação e estatísticas envolvendo a população transgênera no mundo: http://tgeu.org/.
} 
congresso nacional.

O PNE em vigência (2014-2024) contou com amplo debate nacional envolvendo diversos atores governamentais, movimentos sociais, entidades representantes de educadores, sociedade civil (tanto gestores como organizações ligadas ao setor privado) e think tanks ${ }^{7}$, tendo como principal documento para sua elaboração o relatório final da Conferência Nacional de Educação (CONAE) de dezembro de 2010. Nesse relatório do CONAE, a preocupação com a diversidade sexual e de gênero em sala de aula é apontada como eixo central da educação, no Eixo Il do relatório é afirmado:

O tema Educação e diversidade: justiça social, inclusão e direitos humanos constitui o eixo central da educação e objeto da política educacional. Diz respeito à efetivação da educação pública democrática, popular, laica e com qualidade social, banindo o proselitismo, o racismo, o machismo, o sexismo, a homofobia, a lesbofobia e a transfobia nas instituições educativas de todos os niveis, etapas e modalidades. (CONAE, 2010, p.29).

O documento é exemplar ao entender a importância de acolher a diversidade no seio escolar, respeitando as diferenças e garantindo a cidadania de uma parcela vulnerabilizada da população. $\bigcirc$ reflexo desse entendimento torna-se evidente no artigo $2^{\circ}$, II do texto original do PNE:

São diretrizes do PNE a superação das desigualdades educacionais, com ênfase na promoção da igualdade racial, regional, de gênero e de orientação sexual", posteriormente vetado e alterado, retomando o texto do Senado, que fala apenas em "erradicação de todas as formas de discriminação.

A alteração desse trecho no documento sancionado desconfigura o caráter inclusivo ambicionado pelo Plano. Ao tornar o texto genérico e não especificar as variadas subjetividades contempladas no texto original, o documento invisibiliza a diferença.

\section{Análise documental}

Separamos o nosso material nas categorias: (1) manifestações no espaço público formal, (2) manifestações no espaço informal e (3) análises posteriores dos atores. Todos eles estão relacionados temporalmente à votação, daí chamarmos de "antes", "durante" e "depois" do fato.

Vamos observar, basicamente, que o cerne da polêmica é uma discordância. 
Parte de setores do Congresso Nacional, que poderiam ser chamados de conservadores (em sua maioria ligada a diversas vertentes do cristianismo), discordam da noção de gênero como construção histórica e social. Chamaram-na, pejorativamente, de "ideologia de gênero". Do outro lado da polêmica está a vertente mais construtivista, desenvolvida e trabalhada, sobretudo nas teorias pós-identitárias $^{8}$, em textos de autoras como Judith Butler e Guacira Lopes Louro, muito influentes em estudos sobre diversidade sexual e gênero, e que foram institucionalizados nos movimentos descritos na seção anterior. $O$ termo ideologia de gênero, então, é um espantalho dessa vertente e é o que é atacado pelo primeiro ente, o que resulta em uma interação que não corresponde, como será observado, à racionalidade ou crítica pertinente ao debate público.

\section{Pressões no ambiente da política formal: durante o fato}

Nesta categoria alocamos aquelas manifestações/pressões que foram exercidas dentro dos aparelhos formais da democracia moderna: as instituições políticas e a imprensa. Uma primeira evidência é apontada pela matéria intitulada "Pelo menos oito Estados retiram referências a gênero dos planos de educação", do jornal Zero Hora de 29/06/2015. Neste texto, a fala de Marisa Lobo, reconhecida opositora de políticas públicas para a população LGBT e defensora da chamada "cura gay", é a que possui mais ocorrências ao longo do texto. Enquanto outros entrevistados aparecem com apenas uma citação, Marisa Lobo é citada 4 vezes. Além disso, a matéria traz ao todo 5 falas claramente contrárias ao debate de gênero e sexualidade nas escolas, enquanto apenas 4 falas são favoráveis. A diferença é ainda maior na matéria da Folha de São Paulo de 25/06/2015, intitulada "Por pressão, planos de educação de 8 estados excluem ideologia de gênero." Além de trazer o termo "ideologia de gênero" já no título, dos 7 entrevistados apenas um expressa posicionamento claramente favorável a essa discussão nas escolas.

O debate público articulado em torno desse tema acabou sendo pautado por uma espécie de um esvaziamento comunicacional (GOMES, 2008). Segundo esse mesmo autor, na contemporaneidade, o papel da imprensa deixa de ser a de se constituir em:

um meio de debate do qual se espera emergir uma opinião, mas um meio de circulação de opiniões estabelecidas às quais se espera uma adesão, o mais amplamente possivel, de um público reduzido a uma massa chamada de tempos em tempos a realizar decisões plebiscitárias". (GOMES, 2008, p.49).

$8 \quad$ As teorias pós-identitárias são um conjunto de saberes teóricos tributários de pensadores pós-estruturalistas que problematizam as identidades enquanto verdades essenciais e imutáveis do sujeito. 
Mas, Gomes está apontando que, nos dias atuais, essa função informativa perdeu-se, quiçá, historicamente, isto nunca tenha sido aplicado de fato. De qualquer modo, o debate público como pressuposto de uma sociedade democrática distancia-se de seus preceitos autônomos. Enquanto propaganda, a comunicação circulada publicamente adquire um modelo pré estabelecido de uma posição anteriormente consolidada. Como consequência, tem-se a adesão a uma opinião amplamente apoiada por um número muito grande de sujeitos em função de identificação moral ou com valores muito pessoais e, desse modo, privados.

Interessa a essa argumentação, que versa sobre comunicação e debate público, observar o papel que a imprensa exerceu nesse episódio. Ao realizar uma rápida busca na internet pelos termos "kit gay" e "Caderno Escola sem Homofobia", revelou-se uma ampla diferença entre o número de ocorrência entre esses termos. Enquanto o primeiro termo, pejorativo, possui 1.630 .000 resultados, o segundo termo apenas 87.300 resultados. Considerando, ainda, que grande parte dos grandes portais de internet e mídia impressa circulou fortemente o termo "kit gay", é possivel observar como essa circulação colaborou para restringir o debate a estratégias bem determinadas de discussão e de justificação (BOLTANSKI e CHIAPELLO, 2009).

Saindo da imprensa e indo para o espaço de votação das leis, nas esferas, municipal, estadual ou federal, podemos apreciar a pressão pessoalizada na forma de protestos. Na Figura 1, por exemplo, vislumbramos faixas que reafirmam a denominação "Ideologia de gênero". Na primeira, da esquerda para a direita, afirma que o Brasil - talvez em oposição ao internacionalismo socialista - está contra. A segunda afirma que a "Genética define o sexo", aludindo à ausência de determinações que não naturais na definição do segundo. Mas, ressaltamos, essa manifestação ainda não foi feita no palco das votações. Que é o que acontecerá na figura 2.

Figura 1: Protesto

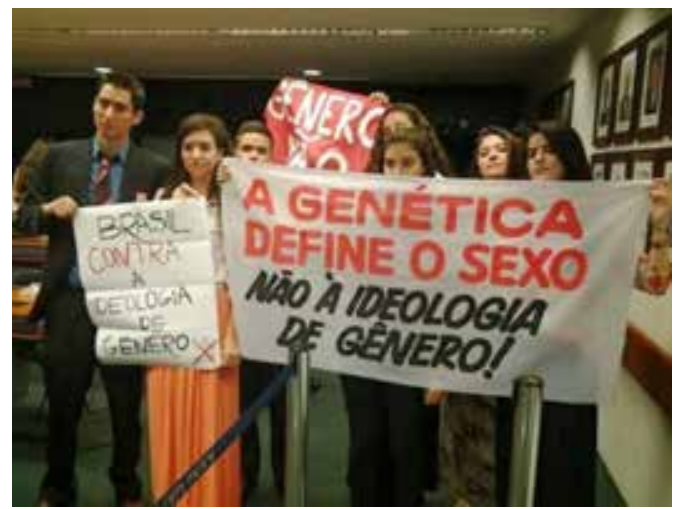

Fonte: http://www.rainhamaria.com.br/Pagina/18090/Por-que-a-Ideologia-de-Generodeve-ser-rejeitada-A-Ideologia-contraria-a-Lei-Divina-e-a-natureza-humana. 
$\mathrm{Na}$ figura 2, gostaríamos de destacar dois elementos: a proximidade com a mesa de votação e um dos cartazes, que traz os dizeres "Na educação escolar de nossos filhos queremos que aprendam: homens e mulheres são diferentes e complementares". Isso implica em uma interpretação do que definiram como ideologia de gênero: a negação da diferença entre homens e mulheres (não tratados como gêneros). Não há, propriamente, uma busca em compreender o referencial teórico construcionista para exercer um contraponto mais embasado, como costuma acontecer nos debates acadêmicos.

Figura 2: Manifestação ocorreu no dia 19 de março de 2014 na Câmara dos Deputados

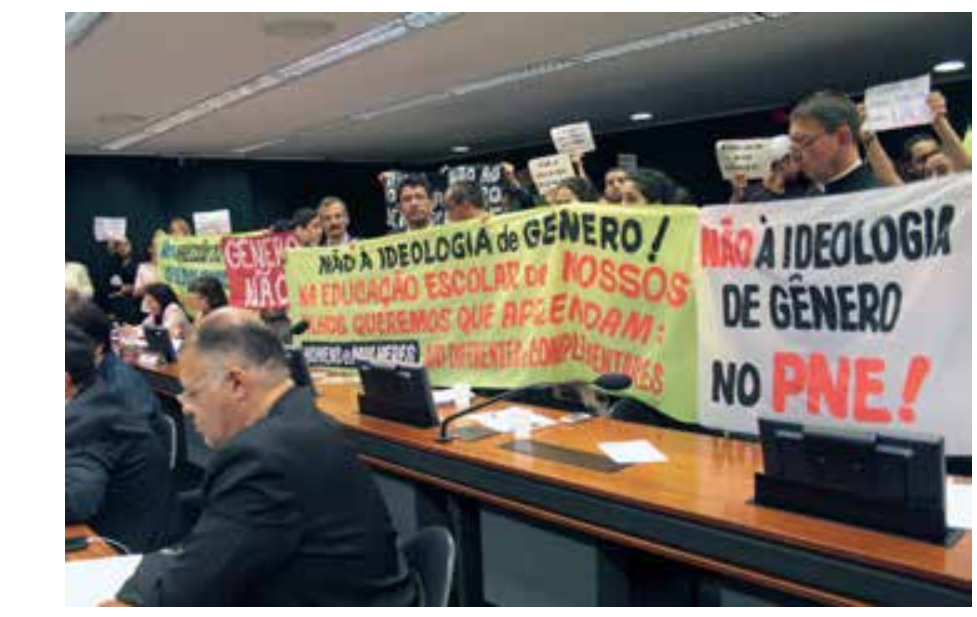

Fonte: http://agnussanctus.blogspot.com.br/2014/03/catolicos-manifestaram-contra-ideologia.html.

\section{Manifestações no espaço informal: antes do fato votação}

Nesta categoria, alocamos as manifestações que não estão nos espaços formais, mas, sim, em espaços de interação que não são diretamente influenciadas pelo governo. Algo como uma esfera pública mesmo, onde a deliberação - não regulada pelo estado - ocorre.

Vamos começar por imagens que circularam na internet. A primeira delas (Figura 3) trata-se de um encarte. Nela temos uma projeção sobre as consequências da aprovação do pacote, como a da uniformidade das pessoas - o que seria o contrário da família, composta por partes que compõe um todo. Poderíamos arriscar que, dadas as pistas dadas pelo material, que se trata de uma família de extração mais patriarcal, na qual as decisões partem e se executam por parte do chefe de família masculino, que não busca a participação de outros membros da família (VITALE, 2002). A utilização do vocábulo "familia tradicional" mais adiante reforça essa avaliação. 


\section{Figura 3 - Encarte}

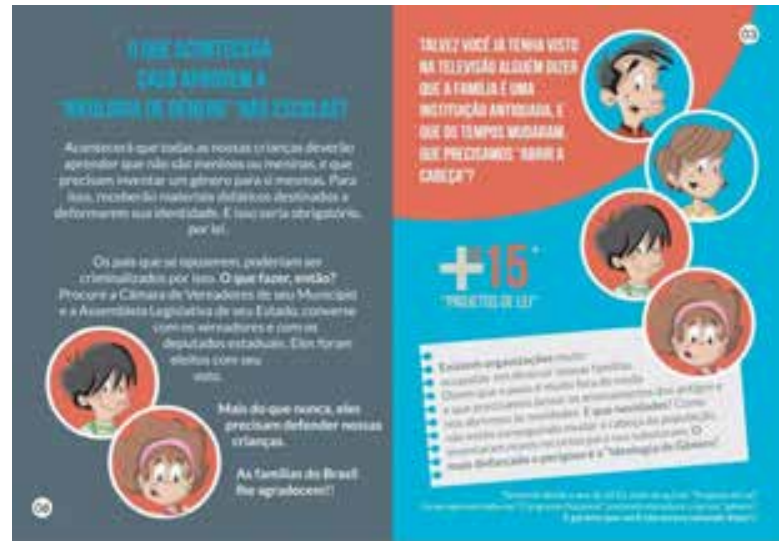

Fonte: http://camposfilho.com.br/novo/wp-content/uploads/2016/02/Cartilha-Ideologia-de-Genero.pdf.

A segunda figura, de extração menos escrita e mais imagética, mostra a consequência imaginada da aprovação através de uma representação pictográfica: a quebra da familia. $O$ que é interessante é que fica sem se saber se o que se está sendo quebrado é a família per se ou se é a representação da família. De qualquer jeito, o epicentro da destruição é exatamente no ponto de união entre o ser identificado como pai e o ser identificado como mãe, na altura dos órgãos sexuais, e, aparentemente, a quebra incide com mais força no menino do que na menina (identificada pelo vestido).

Figura 4 - Imagem de portal cristão

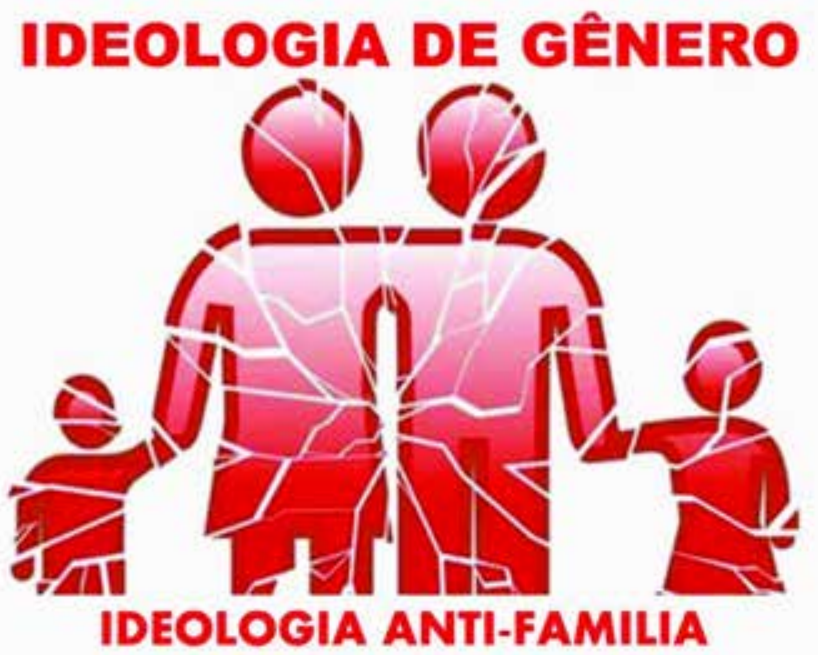

Fonte: http://static.wixstatic.com/media/46eb66_a1dae2269fc24a26a236fb6aabc73604.jpg. 
A terceira imagem se propõe a ser mais informativa, daí uma maior quantidade de texto - embora haja uma tentativa de se "chocar" a partir das fotos de um menino fazendo coisas de "menina". Há uma associação imediata entre o marxismo e a ideologia de gênero - o que a literatura indica ser uma correlação espúria. É proposta a não votação em pleitos eleitorais para políticos que a defendam, o que serve como uma pressão indireta sobre políticos que buscam a reeleição. $O$ objetivo a ser alcançado é manter a "família tradicional" intacta, como um valor fixo em um mundo em mudança.

Figura 5 - Encarte explicativo 9

\section{SAIBA O QUE É A IDEOLOGIA DE GÊNERO}

A Ideologia de Gênero è uma tentativa de afirmar para todas as pessoas que naio existe uma identidade biológica em relação à sexus:lidade. Quer dizer que o sujeito, quando nasce, nd̊o é homem nem mulher, nào possui um sexo masculino ou feminine definido, pois, segundo os ideólogos do género, isto é uma construça social. Ora pode agir com base nos desejos masculinos, ora com base nos

O QUE FAZER DIANTE DESSA TENTATIVA DE DESTRUIR NOSSAS FAMILIAS?

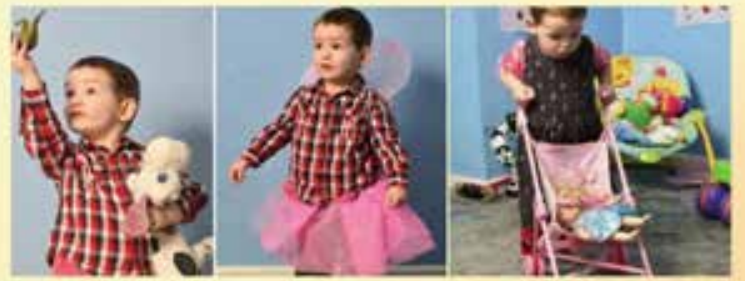

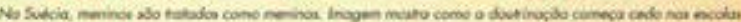

desejos femininos.

Sob essa perspectiva, gènero e uma construcajo pessoal, definida pelo próprio individuo $e_{\text {, com }}$ base nisso, ninguém mals deve ser identificado como homem ou mulher. A destruicáo da familia tradicional sempre foi um objetivo das ideologias marxistas.

No capitulo 2 do Manifesto do Partido Comunista, escrito por Karl Marx e seu parceiro Engels, or autores deixam claro este objetivo: a familia tradicional precisa ser destruida. Com base nessas teorias, inúmeras organizaçóes politicas ligadas a partidos de esquerda, vêm debatendo idelas o pretexto de eliminar preconcei tos e discriminaçôes, a destruiçảo da familia tradicional. cuja finalidade é levar adiante, sob

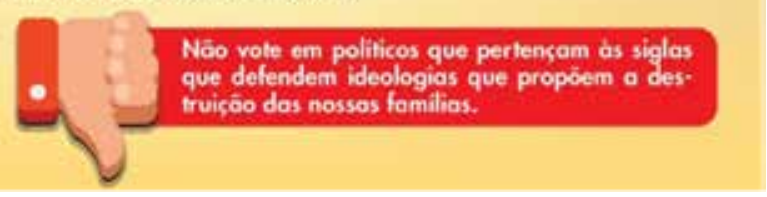

Fonte:http://deputadopaulofreire.com.br/paulo-freire-defendeu-a-familia-e-disse-nao-a-ideologia-de-genero.

Nesse ponto, seria interessante fazer um paralelo com estudos sobre religiões de matriz africana, pois parece que repete-se um modus operandi. A partir dele, é possivel perceber uma "guerra santa", movida pela chamada bancada evangélica contra algumas demandas da sociedade civil:

\footnotetext{
9 É importante ressaltar que uma investigação mais focada revelou uma outra origem para a imagem utilizada, divergente daquela informada no material. Nossa busca indicou que essas fotos foram utilizadas em uma matéria sobre um casal britânico que resolveu criar o filho de forma neutra. Ou seja, não haveria relação nem com a Suécia e nem com alguma suposta legislação de algum país. Ademais, seria uma decisão privada. A matéria pode ser conferida no site: http://www. dailymail.co.uk/news/article-2559748/If-Max-wants-wear-pink-tutu-fairy-wings-Parents-raise-son-boy-AND-girl-wont-grow-aggressive.html.
} 
De fato, a "bancada religiosa" no Congresso Nacional foi decisiva para barrar os projetos de lei que concernem a descriminalização do aborto, a união civil entre pessoas do mesmo sexo, as pesquisas com células-tronco embrionárias e a realização de cirurgias de mudança de sexo (transgenitalização) pelo Sistema Único de Saúde (SUS). É certo, porém, como se sabe, que partes dessas demandas foram atendidas pelo Supremo Tribunal Federal. (ORO e JUNIOR, 2013, p. 124).

O que ocorre é uma pressão direcionada diretamente para o legislativo, efetivada por representações estigmatizadas, cuja capacidade de difusão se encontra também no espaço da internet. Isso remete às semelhanças com a situação das religiões afro:

Finalmente, a quarta dimensão tipificada nessa polêmica diz respeito aos significados da própria guerra santa empreendida pelos segmentos evangélicos, sobretudo aqueles de confissão neopentecostal. Nessa perspectiva, as históricas lógicas de repressão e de intolerância religiosa projetadas sobre as religiões afrobrasileiras são atualizadas, em dois sentidos principais: a) a disseminação de um senso comum dotado de representações estigmatizadas, antes efetuada pela mídia convencional, e agora revigorada através do agendamento midiático evangélico, no qual os cultos afro-brasileiros são demonizados e suas divindades exorcizadas publicamente, numa espécie de produção sistemática de sentidos negativos atribuídos às religiões afrobrasileiras; b) a repressão legal outrora empreendida pelo Estado católico passa a ser efetivada com base em proposições legislativas dissimuladas, advindas da atuação de parlamentares pertencentes à bancada evangélica [grifos nossos]. (LEISTNER, 2013, p. 227).

Portanto, esquecer desse contexto maior poderia nos fazer perder de vista essa "guerra santa", que é o que motiva fortemente um dos lados do debate público. Mas é interessante que a repercussão também possa indicar se o pavio dessa chama já se consumiu de todo, pois, se ele ainda houver, o debate público se reabre em algum momento, e a controvérsia se reaviva em outros termos.

\section{Análises dos atores após o fato}

Se, em um primeiro momento, analisamos reflexões de primeira ordem que destinaram-se a determinar os resultados da discussão, agora queremos abordar uma reflexão de segunda ordem. Estas analisam os resultados da primeira deliberação.

A primeira análise que gostariamos de ressaltar é a do artigo $O$ que é a ideologia de gênero que foi banida dos planos de educação afinal?, de lzabelle 
Mundim (2015). A autora, no caso, afirma enxergar o conflito entre dois lados. A começar pelo lado que se saiu vencedor e que determinou o escopo do debate:

\begin{abstract}
$\mathrm{Na}$ ocasião, as bancadas religiosas afirmaram que essas expressões valorizavam uma "ideologia de gênero", corrente que deturparia os conceitos de homem e mulher, destruindo o modelo tradicional de família. O PNE também incluía temas como número de alunos por sala, remuneração de professores e repasse de verbas para a educação, mas a questão de gênero acabou dominando a discussão. (UOL EDUCAÇÃO, 2015, s/p).
\end{abstract}

O outro lado foi denominado como:

Movimentos pró-direitos humanos e direitos LGBT consideram a inclusão do debate de gênero nas escolas fundamental para combater a discriminação e a violência física e psicológica de gênero contra lésbicas, gays, transexuais e mulheres e afirmam ser papel do Estado promover, através da educação, o respeito à diversidade. (UOL EDUCAÇÃO, 2015, s/p).

Ou seja, a autora focou-se em uma dualidade e nas suas consequências na não implantação. Ela levanta os pontos que ficaram de fora por conta dessa animosidade, o que mostra que o debate público não foi proveitoso para outras questões educacionais.

Já o jornalista Leonardo Sakamoto (2015), em seu blog, jogou luz sobre prática da imprensa nesse episódio:

O absurdo rivaliza, talvez, com a ação de parlamentares que colocam o fundamentalismo religioso acima da garantia da dignidade, com a falta de coragem do governo federal, que engavetou o material, e o comportamento de colegas jornalistas que ajudaram a batizar esse material didático de "Kit Gay", reduzindo a complexidade da discussão e ajudando a reafirmar preconceitos em nome da audiência. (SAKAMOTO, 2015).

Os jornalistas envolvidos na divulgação das informações buscaram o bem privado - a audiência, que é convertida em lucro financeiro - ao invés do bem público - que seria beneficiado por um debate complexificado e verdadeiro atento a argumentos ad res. Assim, é identificada uma das tendências, a da redução do 
público a um privado em específico.

\section{Tendências do debate público}

Gostaríamos de apontar para algumas tendências encontradas no material, para, assim, tentar entender como o debate público transcorreu até o encerramento da pauta. $O$ primeiro elemento presente é recorrência de valores marcadamente religiosos, de cunho privado, que assumem uma importância pública ao situar-se no âmbito político. Ao realizar uma nova pesquisa em buscadores da internet com o termo "ideologia de gênero" encontra-se facilmente materiais que identificam na mera utilização do termo "gênero" uma ameaça e uma ideologia perversa orientada para a destruição da família e seus valores, compreendendo família aqui como tradicional e heteronormativa. É possivel observar também que grandes portais jornalísticos pouco esclareceram sobre a noção construtivista de gênero. Além de também contribuir para a popularização do termo "ideologia de gênero" que facilmente aparece em manchetes de grandes jornais e portais de notícias.

Esse tipo de prática jornalística estabelece-se, assim, como uma forma de poder ao controlar e delimitar a linguagem que medeia os acontecimentos. Segundo Esteves (2011), o poder do jornalismo coloca-se como uma autoridade que impõe certa visão de mundo, geralmente de acordo com uma perspectiva já estabelecida como hegemônica. Constituída a partir de "uma linguagem ultrasimplificada, pessoalizada e descontextualizada" e que "privilegia o estereótipo em detrimento da complexidade" (ESTEVES, 2011, p.256). Tal prática, segundo Gomes (2008), configura uma nova opinião pública, que rompe com um modelo iluminista (constituído no uso público da razão). Ela assume apenas uma aparência superficial de interesse público, sendo engendrada por interesse privado de grupos previamente organizados. Assim, o papel da imprensa deixa de ser:

um meio de debate do qual se espera emergir uma opinião, mas um meio de circulação de opiniões estabelecidas às quais se espera uma adesão, o mais amplamente possivel, de um público reduzido a uma massa chamada de tempos em tempos a realizar decisões plebiscitárias. (GOMES, 2008, p.49).

Observa-se que, nesse sentido, opera uma circulação e uma difusão dessas opiniões estabelecidas previamente ao debate público. Ao contrário de constituirse como um espaço de discussão e crítica, com abertura para o inesperado. Configura-se, assim, mais uma espécie de propaganda, segundo Gomes (2008), pois orienta-se a cooptar uma grande quantidade de individuos motivada por uma identificação superficial e imediata baseada em emoções, excluindo-se, assim, uma deliberação racional, sensivel às diferenças e buscadora de um crescimento mútuo. 
Outra característica observável é a assimetria de vozes envolvida nesse debate específico. McQuail (2012) defende que a pluralidade de vozes presentes na mídia são garantias de qualificação do debate e configuram-se como "armas essenciais para resistir às tendências de controle centralizado e uniformidade". No entanto, algumas das matérias acessadas conferem um peso mais significativo às falas contrárias ao gênero e sexualidade no PNE. Nesse sentido, o debate desenvolvese de forma assimétrica, uma vez que a opinião conservadora acaba por ter mais presença e espaço. O pluralismo é afetado e, como consequência, a população LGBT, parcela já marginalizada e discriminada da sociedade, perde também em espaço no debate. Nota-se aqui, uma condição que contraria aquilo que Esteves (2011) define como princípios da estrutura da comunicação pública. Um deles é o de não fechamento do público e o outro, o de não fechamento temático. O primeiro princípio implica a ampla participação de todos sem restrição dos indivíduos no espaço público, enquanto o segundo pressupõe uma laicização da cultura e da política, em prol de uma racionalidade que permeie o debate. Esse pressuposto é oriundo de uma ruptura frontal com uma moral religiosa e mais tradicional a partir do iluminismo.

A realidade empírica, no entanto, oferece um cenário divergente. No Brasil, hoje, os grupos religiosos e conservadores detém poder político e, sobretudo, econômico. Esses grupos ligados às igrejas neopentecostais possuem não somente cadeiras no congresso, como também são proprietários dos próprios veículos e espaços de comunicação. Desse modo, esses grupos circulam amplamente sua visão de mundo e estimulam a adesão a ela por parte de fiéis e não fiéis. Observa-se, assim, que, não raro, interesses de viés econômico ou baseados em valores pessoais, portanto privados, acabam por influenciar e pautar a imprensa (Gomes, 2008) comprometendo um amplo debate público acerca de temáticas mais progressistas.

\section{Considerações finais}

A argumentação desenvolvida até aqui pressupõe o entendimento da noção de esfera pública, por oposição à esfera privada. Tais noções são questões fundamentais para pensar as possibilidades de um debate amplamente público como condição de uma sociedade democrática, ou seja, considerando que a sociedade democrática somente pode ser pensada a partir de um debate público, plural, onde as diversas vozes desfrutem de igualdade de oportunidades nessa esfera pública. A partir desses conceitos, evidencia-se também que o debate público somente é qualificado se tem como condição intrínseca a argumentação racional.

Nesse sentido, ao contrário do que Arendt (2003) observa na Grécia em seu período clássico, o espaço público no estado moderno passa a se organizar em função do trabalho e da economia, desse modo, há uma espécie de sobreposição do privado no público, promovendo um estreitamento desse último. A política 
assim perde em espaço e a consequência prática desse processo, é, igualmente, a perda de espaço do debate público. Dito de outro modo, o espaço da prática política se perde à medida que o debate público é pautado pelos interesses privados e não mais ao bem comum e coletivo.

A importância de evidenciar esse processo configura um desvelar das condições precárias em que o debate sobre o Plano Nacional de Educação se desenvolveu na sociedade. A imprensa, por sua vez, acabou por chancelar um debate pouco qualificado que acabou convergindo para opiniões já estabelecidas em um espectro conservador e fundamentalmente dependente de uma moral privada desse segmento da população. Ao circular, difundir e consolidar os termos "ideologia de gênero" e "kit gay", apela-se ao um sensacionalismo que visa, principalmente, uma adesão imediata e pouco reflexiva dos argumento em disputa. Além disso, a pluralidade de ideias e posições são comprometidas provocando uma assimetria no debate público. No caso do debate examinado aqui, a parcela ainda marginalizada da população, e que se sentia contemplada no texto original do PNE, perdeu espaço no debate e se viu solapada pela opinião pública de que a escola não é lugar de trabalhar questões de gênero.

Gostaríamos de encerrar esse texto com a afirmativa, talvez um tanto polêmica, de que a ascensão dos segmentos neopentecostais não está "contaminando" a política com religiosidade. A religião católica sempre esteve fortemente conectada com a política desde o surgimento da colônia, e sua influência é tão forte que se torna invisibilizada. O que é interessante mesmo é a questão da divisão do campo político, que é o que de fato origina o grupo de pressão, levando-nos a pensar sobre a religião e o espaço público:

\footnotetext{
Por outro lado, as religiões não possuem mais lugar no espaço público, ou, ao contrário, elas nunca dele se ausentaram, não somente pela sua logística, mas, também, pela inscrição dos seus símbolos em monumentos, locais públicos, recintos estatais e ultimamente nas mídias e na política? (ORO e JUNIOR, 2013, p. 112).
}

Ou seja, o catolicismo, por exemplo, esteve sempre presente na dimensão pública. E estamos presenciando, justamente a tentativa neopentecostal de chegar ao mesmo nível de participação, daí a sua agressividade de outsider. Encerramos nossas preleções com as palavras de Oro e Junior (2013, p. 141): "[...] religião e política [...] são instâncias em constante rearticulações, que produzem novas combinações, pressupondo-se que se trata de dimensões que, malgrado vozes em contrário, nunca estiveram definitivamente desconectadas mas, antes, são sempre reordenadas". 


\section{Referências}

ADORNO, T. Indústria Cultural e Sociedade. Rio de Janeiro, Paz e Terra, 2002.

ARENDT, H. A Condição Humana. Rio de Janeiro, Forense Universitária, 2003.

ARISTÓTELES. Ética - A Nicômaco. São Paulo, Martin Claret, 2002.

BOLTANSKI, Luc; CHIAPELLO, Ève. O novo espírito do capitalismo. São Paulo: Martins Fontes, 2009.

BRASIL. Comitê Nacional de Educação em Direitos Humanos. Plano Nacional de Educação em Direitos Humanos: 2007. Brasilia: Secretaria Especial dos Direitos Humanos, 2007. 76 p.6.

Lei 13.005, de 25 de junho de 2014. Aprova o Plano Nacional de Educação e dá outras providências. Disponivel em < http://www2.camara.leg.br/legin/fed/ lei/2014/lei-13005-25-junho-2014-778970-publicacaooriginal-144468-pl. html>. Acesso em 14 de julho de 2016.

Lei n $9394 / 96$, de 20 de dezembro de 1996. Estabelece as Diretrizes de Bases da Educação Nacional. Disponivel em < http://www.planalto.gov.br/ ccivil_03/leis/L9394.htm>. Acesso em 15 de julho de 2016.

Ministério da Educação. Conae 2010: Conferência Nacional de Educação. Disponivel em: http://conae2014.mec.gov.br/images/pdf/doc_referencia.pdf . Acesso em 20 de julho de 2016.

Ministério da Educação. Nota Técnica no 24/2015. Orientação aos Sistemas de Ensino para a implementação da Lei $n^{0}$ 12.764/2012. Disponivel em<http://portal.mec.gov.br/index.php?option=com docman\&view=download\&alias=13287-nt24-sistem-lei12764-2012\&categoryslug=junho-2013-pdf\&Itemid=30192.> Acesso em 15 de julho de 2016.

. Secretaria Especial dos Direitos Humanos. Plano Nacional de Promoção da Cidadania e Direitos Humanos de Lésbicas, Gays, Bissexuais, Travestis e Transexuais.

CONSELHO NACIONAL DE COMBATE À DISCRIMINAÇÃO. Brasil Sem Homofobia: Programa de combate à violência e à discriminação contra GLTB e promoção da cidadania homossexual. Brasili: Ministério da Saúde, 2004.

DE OLHO NOS PLANOS. Disponivel em http://www.deolhonosplanos.org. brl. Acesso em 2 de julho, 2016.

CADERNO ESCOLA SEM HOMOFOBIA. Gênero e diversidade na escola: 
formação de professoras(es) em gênero, orientação sexual e relações étnicoraciais. Rio de Janeiro: CEPESC, Brasilia: SPM, 2009.. Disponivel em: http:// revistaescola.abril.com.br/pdf/kit-gay-escola-sem-homofobia-mec.pdf. Acesso em 13 de julho de 2016.

EISENSTADT, Shmuel N. Modernidades múltiplas. Sociologia, problemas e práticas. Lisboa, 2001, n. 35, p. 139-163.

ESTEVES, J. P. Sociologia da Comunicação, Lisboa: Fundação Calouste Gulbenkian, 2011.

GOMES, W. S.; MAIA, R.C.M. Comunicação e Democracia: Problemas e Perspectivas. São Paulo: Paulus, 2008.

JOVCHELOVITCH, Sandra. Os contextos do saber: representações, comunidade e cultura. Petrópolis, RJ : Vozes, 2011.

JUNQUEIRA, R. D. (Org.). Diversidade sexual na educação: problematizações sobre Homofobia nas escolas. Brasilia: Ministério da Educação/Secretaria de Educação Continuada, Alfabetização e Diversidade/UNESCO, 2009.

LATOUR, Bruno. Jamais fomos modernos. Editora 34, 1994.

LEISTNER, Rodrigo Marques. Religiões de Matriz Africana do Rio Grande do Sul: entre conflitos, projetos políticos e estratégias de legitimação. Debates do NER, v. 1, n. 23, p. 219-246, 2013.

LOURO, G. L. Um Corpo Estranho: Ensaios Sobre Sexualidade e Teoria Queer. Belo Horizonte: Autêntica, 2004.

McQUAIL, D. Atuação da Mídia, comunicação de massa e interesse público. Porto Alegre: Penso, 2012.

ORO, Ari Pedro; JUNIOR, Erico Tavares de Carvalho. Religiões e eleições 2012 em Porto Alegre. Debates do NER, v. 1, n. 23, 2013, p. 109-144.

SOUZA, Celina. Políticas públicas: uma revisão da literatura. Sociologias, v. 8 , n. 16, p. 20-45, 2006.

UOL EDUCAÇÃO. O que é a ideologia de gênero que foi banida dos planos de educação afinal? Reporte: Izabelle Mundim, 11 de agosto de 2015. Disponivel em: https://educacao.uol.com.br/noticias/2015/08/11/o-que-e-a-ideologia-degenero-que-foi-banida-dos-planos-de-educacao-afinal.htm. Acessado em 12 de abril de 2016.

SAKAMOTO, Leonardo. Baixe o "Escola sem Homofobia" - chamado por intolerantes de "Kit Gay" Uol Notícias. 2015. Disponivel em: https:// 
blogdosakamoto.blogosfera.uol.com.br/2015/02/11/baixe-o-escola-semhomofobia-chamado-por-intolerantes-de-kit-gay/?cmpid=copiaecola. Acesso em 2 de julho, 2016.

VITALE, M. A. F.. Famílias monoparentais: indagações. Revista Serviço Social \& Sociedade, São Paulo, v.1, n.71, 2002, pp. 31-53.

Recebido em março de 2017.

Aprovado em setembro de 2018. 